\title{
Biphasic glycerol/2-MeTHF, ruthenium-catalyzed enantioselective transfer hydrogenation of ketones using sodium hypophosphite as hydrogen donor
}

\author{
Carole Guyon, ${ }^{[a]}$ Estelle Métay, ${ }^{[\mathrm{a}]}$ Nicolas Duguet, ${ }^{[\mathrm{a}]}$ and Marc Lemaire ${ }^{[\mathrm{a}], *}$
}

Keywords: Reduction / Ketone / Enantioselective / Ruthenium / Sodium hypophosphite / Glycerol

Sodium hypophosphite has been used as efficient hydrogen donor in transfer hydrogenation of aliphatic and aromatic ketones using $\left[\mathrm{RuCl}_{2}(p \text {-cymene })\right]_{2}$ and 2,2'-bipyridine in water. The corresponding alcohols were isolated with moderate to excellent yields (39-95\%). Good chemoselectivities were observed since ester, nitrile and halide groups were not reduced. [a] Equipe Catalyse Synthèse et Environnement, Institut de Chimie et Biochimie Moléculaires et Supramoléculaires

UMR 5246, Université Claude Bernard Lyon 1, Bâtiment Curien, 43 boulevard du 11 novembre 1918 F-69622 Villeurbanne Cedex, France Fax: (+33)-4-72-43-14-08; phone: (+33)-4-72-43-14-07; e-mail: marc.lemaire.chimie@univ-lyon1.fr Supporting information for this article is available on the WWW under http://www.eurjoc.org/ or from the author.

\section{Introduction}

The reduction of ketone is widely employed in the laboratory as well as in industry. ${ }^{[1]}$ Efficient reduction systems have been developed using neutral and charged hydrides, ${ }^{[2]}$ molecular hydrogen, ${ }^{[3]}$ hydrogen donors (isopropanol, triethylamine/formic acid, sodium formate), ${ }^{[4]}$ hydrosilanes ${ }^{[5]}$ and hydrosiloxanes. ${ }^{[5]}$

Molecular hydrogen remains the most attractive reductant from both cost and atom economy points of view. However, the lack of selectivity observed in many cases, the flammability of this gas and the specialized equipment required led to the search of alternatives. Aluminium and boron hydrides present safety and environmental concerns. They are highly reactive towards air and moisture hence a careful quenching is usually required to avoid any risk of fire. In addition, the toxicity of the water-soluble solvents used and the one of the generated by-product salts are also a serious limitation. ${ }^{[6]}$

The reduction using alcohols (mainly isopropanol) as hydrogen donors is an equilibrium. ${ }^{[4 \mathrm{~b}]} \mathrm{A}$ high dilution is usually preferred in order to reach high conversions. Triethylammonium formate releases unrecyclable triethylamine. Hydrosilanes can disproportionate to $\mathrm{SiH}_{4}$, a pyrophoric and toxic gas. ${ }^{[7]}$ Consequently, the development of new reductive systems which are efficient, selective and cheap (reaction and treatment), with low environmental impact and toxicity is highly desirable. Efforts have been directed towards the use of hydrosiloxanes, which are non-pyrophoric, air-stable and non-toxic reagents. In our group, efficient methods using tetramethyldisiloxane associated with a metal were developed for the reduction of several functional groups. ${ }^{[8]}$ To date, the price of this reagent is one of the limitations of its use at an industrial scale.

Looking for other reductive agents, we have been interested in sodium hypophosphite $\mathrm{e}^{[\mathrm{a}]}$ and its derivatives (i.e. phosphinic acid $)^{[\mathrm{gb}]}$. Sodium hypophosphite is an easy-to-handle solid, stable to air and moisture, available in bulk quantity and already registered in $\mathrm{REACH}$ as a chemical presenting no obvious toxicity. ${ }^{[10]}$

Sodium hypophosphite and phosphinic acid are known as reductive reagents associated with metal catalysts. ${ }^{[9]}$ In comparison with their large industrial use for electroless nickel plating for example, ${ }^{[11]}$ they have been less studied for the reduction of functional groups. Sodium hypophosphite derivatives are mainly employed in heterogeneous transfer hydrogenation ${ }^{[12]}$ catalyzed by $\mathrm{Pd} / \mathrm{C}^{[13,18]}$ or Raney nickel. ${ }^{[14]}$ Comparatively, few examples have been reported with copper, ${ }^{[15]}$ iron $^{[16]}$ and ruthenium in homogeneous catalysis. ${ }^{[14 \mathrm{~g},}{ }^{17}$ Reductions catalyzed by $\mathrm{Pd} / \mathrm{C}$ are generally not selective. ${ }^{[18 \mathrm{c}]}$ Activated ketones are an exception and could be converted to either alcohols ${ }^{[18 a]}$ or alkanes. ${ }^{[18 b]}$ Iridium tetrachloride in association with phosphinic acid or phosphorous acid in water/ $i \mathrm{PrOH}$ allows the reduction of cyclic ketones with good diastereoselectivities (cis/trans ratio $=97: 3$ for 4-tertbutylcyclohexanone). ${ }^{[19]}$ A ruthenium-catalyzed reduction has also been developed using triethylammonium hypophosphite as reductant and solvent leading to good stereo- and chemoselectivities. ${ }^{[14 \mathrm{~g}, 17 \mathrm{~b}]}$ Despite the efficiency of these methods, they are plagued by the use of water-soluble solvents and the use of triethylamine in excess. To the best of our knowledge, no enantioselective reduction of prochiral aromatic and linear aliphatic ketones has been reported using hypophosphite derivatives as reductant.

Herein, we report the first reduction of ketones with sodium hypophosphite in a biphasic system using $\left[\mathrm{RuCl}_{2}(p \text {-cymene })\right]_{2}$ and 2,2'-bipyridine into the corresponding racemic alcohols. The enantioselective version using the well-known Noyori's catalyst $\mathrm{RuCl}(p$-cymene)-TsDPEN in 2-MeTHF/glycerol biphasic solvent mixture is also described with good chemo- and enantioselectivities.

\section{Results and Discussion}

Homogeneous ruthenium catalysts are well known for the chemoselective reduction of ketones under transfer hydrogenation conditions ${ }^{[4]}$ Consequently, we focused our study on ruthenium species as catalysts. Khai et al. ${ }^{[14 \mathrm{~g}, 17 \mathrm{~b}]}$ have successfully used $\mathrm{RuCl}_{2}\left(\mathrm{PPh}_{3}\right)_{3}$ for the reduction of ketones by triethylamine/phosphinic acid mixture. First, we have been interested in a biphasic version of this reaction using sodium hypophosphite as reductive reagent in water. The reduction of acetophenone by sodium hypophosphite ( 5 equiv.) catalyzed by 
$\mathrm{RuCl}_{2}\left(\mathrm{PPh}_{3}\right)_{3}$ under biphasic conditions (toluene/water) in the presence of a phase transfer catalyst $(n \mathrm{Bu} 4 \mathrm{NCl})$ gave a conversion of $20 \%$ (Table 1, entry 1 ). Water-soluble phosphine ligand TPPTS (tris ( $m$-sulfophenyl)phosphine trisodium salt) with $\mathrm{RuCl}_{3} \cdot \mathrm{xH}_{2} \mathrm{O}^{[20]}$ was also evaluated without improvement of the conversion (Table 1, entry 2). Nitrogenated ligands were then tested with different $\mathrm{Ru}(\mathrm{II})$ and $\mathrm{Ru}(\mathrm{III})$ precursors. The best conversion observed with $\mathrm{RuCl}_{3} \cdot \mathrm{xH}_{2} \mathrm{O}$ was $42 \%$ when 1,10 phenanthroline was used as ligand (Table 1, entry 3). With the commercially available preformed bipyridine ruthenium complex, the reduction was less efficient (Table 1, entry 4). Satisfyingly, the association of 2,2'-bipyridine and $p$-cymene complex (1 mol$\%$ ) without toluene and $n \mathrm{Bu} 4 \mathrm{NCl}$ at $80{ }^{\circ} \mathrm{C}$ gave a complete conversion of acetophenone (Table 1, entry 5).

Table 1. Study on the ruthenium complex effect.

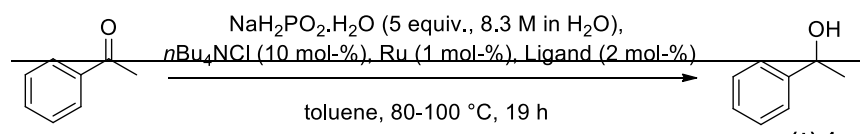

\begin{tabular}{|c|c|c|c|}
\hline & & & $( \pm)-1$ \\
\hline Entry & Ruthenium complex & Ligand & Conv. $[\%]^{[\mathrm{a}]}$ \\
\hline 1 & $\mathrm{RuCl}_{2}\left(\mathrm{PPh}_{3}\right)_{3}$ & None & 20 \\
\hline $2^{[\mathrm{b}]}$ & $\mathrm{RuCl}_{3} \cdot \mathrm{xH}_{2} \mathrm{O}$ & TPPTS (4.5 mol\%) & $<5$ \\
\hline 3 & $\mathrm{RuCl}_{3} \cdot \mathrm{xH}_{2} \mathrm{O}$ & 1,10-phenanthroline & 42 \\
\hline $\begin{array}{l}4 \\
5^{[\mathrm{b}, \mathrm{c}]} \\
\end{array}$ & $\begin{array}{l}\mathrm{RuCl}_{2}(\mathrm{biPyr})_{2} \\
{\left[\mathrm{RuCl}_{2}(p \text {-cymene })\right]_{2}}\end{array}$ & $\begin{array}{l}\text { None } \\
2,2 \text { '-bipyridine }\end{array}$ & $\begin{array}{l}15-24 \\
98\end{array}$ \\
\hline
\end{tabular}

[a] Conversions were determined by ${ }^{1} \mathrm{H}$ NMR spectroscopy. [b] No phase transfer agent and no co-solvent were used. $[c]\left[\mathrm{RuCl}_{2}(p \text {-cymene })\right]_{2}(1$ mol-\%), 2,2'-bipyridine (2.4 mol-\%).

This result indicates that neither a phase transfer agent nor a co-solvent were necessary to reach high conversions under these conditions. Additional experiments showed that the amount of sodium hypophosphite could be reduced from 5 to 2.5 equivalents without significant loss of conversion. As a consequence, the reduction of a range of ketones was carried out in water in the presence of sodium hypophosphite (2.5 equiv.) with 1 mol-\% of $\left[\mathrm{RuCl}_{2}(p \text {-cymene })\right]_{2}$ and 2.4 mol-\% of $2,2^{\prime}$-bipyridine at $80{ }^{\circ} \mathrm{C}$ for 18 to 24 hours.

The reduction of acetophenone derivatives was not sensitive to the length of the alkyl chain (Table 2, entries 1 and 2). 2Acetonaphthone was also converted to alcohol $\mathbf{3}$ in good yield (Table 2, entry 3 ). The reduction was chemoselective towards halogen, nitrile and ester groups under these conditions (Table 2, entries 4-6). It should be noted that, in the case of $p$ cyanoacetophenone and the ester derivative, a co-solvent was necessary to reach good yields and selectivities (Table 2, entries 5 and 6). Furthermore, alkyl ketones could also be reduced and isolated in $75 \%$ and $50 \%$ yield (Table 2, entries 7 and 8). Finally, benzophenone was reduced in $39 \%$ yield (Table 2, entry 9).
Table 2. Reduction of ketones

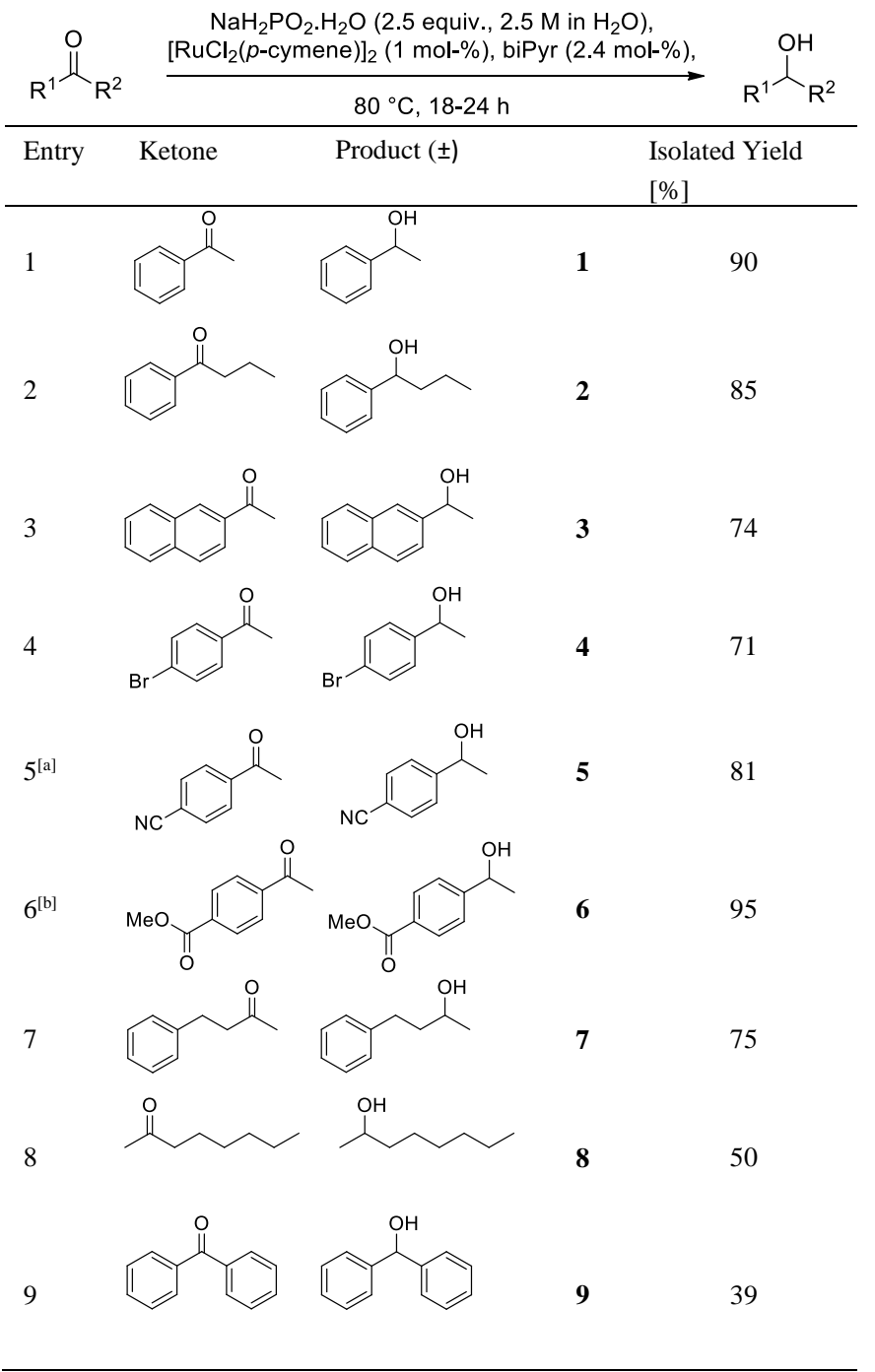

[a] Toluene was used as co-solvent $([\mathrm{S}]=2.5 \mathrm{M})$. [b] 2-MeTHF was used as co-solvent $([\mathrm{S}]=2 \mathrm{M})$.

From these encouraging results, an enantioselective version of this reaction was then explored. To the best of our knowledge, only one report describes an enantioselective reduction of cyclic ketones with an ammonium hypophosphite. ${ }^{[17 b]}$ Considering the lack of knowledge about sodium hypophosphite, it was interesting to evaluate its potential in the enantioselective reduction of ketones.

A recent review ${ }^{[21]}$ concerning enantiopure bipyridines mentioned that these ligands were inducing relatively poor enantiomeric excesses in the reduction of ketones. Thus, other nitrogenated ligands were preferentially investigated. All optimized parameters ( 2.5 equiv. of $\mathrm{NaH}_{2} \mathrm{PO}_{2} \cdot \mathrm{H}_{2} \mathrm{O}$ as $2.5 \mathrm{M}$ in water, $1 \mathrm{~mol}-\%$ of $\left.\left[\mathrm{RuCl}_{2}(p \text {-cymene })\right]_{2}\right)$ were kept except the temperature that has been lowered in order to reach better enantiomeric excess. The nature of the ligand (2.4 mol-\%) was first probed (Scheme 1). Oxazoline-based ligands have been reported to induce good enantioselectivity in the hydrosilylation of ketones ${ }^{[22 \mathrm{a}]}$ and in the transfer hydrogenation with $i \mathrm{PrOH} .{ }^{[22 \mathrm{~b}]}$ However, they have been found inefficient to induce a conversion under these conditions (Scheme 1, L1 and $\mathbf{L 2}$ ). The ligand $\mathbf{L 3}$ has 
been used in asymmetric transfer hydrogenation with formate ${ }^{[23]}$ but no conversion was observed under our conditions. The reaction performed with cyclohexane-1,2-diamine (L4) gave a modest conversion of $50 \%$ and a poor enantiomeric excess (5\%). Finally, 1,2-diphenyl-1,2-ethylenediamine ligands were engaged in the reduction of acetophenone. $C_{2}$-symmetric $(R, R)$-DPEN (L5) gave a moderate yield with $20 \%$ enantiomeric excess. Conversely, with the Noyori's ligand $(R, R)$-TsDPEN (L6), $87 \%$ $e e$ was reached. This ligand was successfully used for the reduction of ketones in the presence of the same ruthenium complex in water with sodium formate. ${ }^{[24]}$ Afterwards, we focused our investigation on the Noyori's ligand $(\operatorname{RuCl}(p-$ cymene)-TsDPEN) giving the best enantioselectivity but a poor conversion.

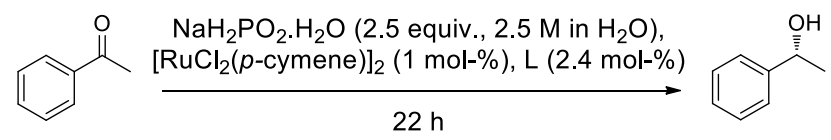

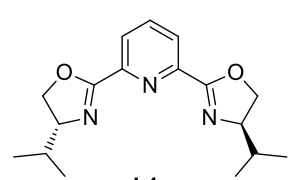

L1

$\mathrm{T}=40^{\circ} \mathrm{C}$

$2 \%$, N.D. $e e^{*}$

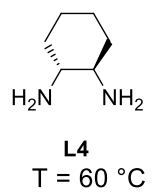

$50 \%, 5 \%$ ee

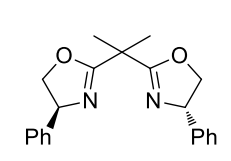

$\mathrm{T}=40^{\circ} \mathrm{C}$

$0 \%$, N.D. $e e^{*}$

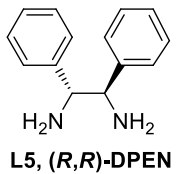

$\mathrm{T},(\boldsymbol{R}, \boldsymbol{R})$-DPEN
$\mathrm{T}=60{ }^{\circ} \mathrm{C}$

$50 \%, 20 \%$ ee
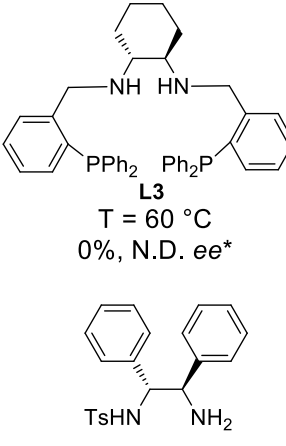

L6, $(R, R)$-TSDPEN

$\mathrm{T}=40^{\circ} \mathrm{C}$

$20 \%, 87 \%$ ee

Conversion calculated by ${ }^{1} \mathrm{H}$ NMR, ee determined by chiral GC ${ }^{*}$ N.D.: not determined

Scheme 1. Screening of ligands.

Because of the lack of reactivity of the catalyst observed in water, we considered replacing water by other polar solvents. Data concerning the solubility of sodium hypophosphite are only available for water (51.96 wt.-\%) and glycols: ethylene glycol (33.01 wt.-\%), glycerol (32.70 wt.-\%) and propylene glycol (9.70 wt.-\%) at $25{ }^{\circ} \mathrm{C} .{ }^{[25]}$ The optimisation was pursued with glycerol which is considered as a green solvent according to the GSK's solvent selection guide (Table 3). ${ }^{[26]}$

A control experiment without hypophosphite salt did not give any conversion (Table 3 , entry 1 ). This observation suggests that glycerol is not acting as a hydrogen donor ${ }^{[27]}$ under these conditions. The concentration of hypophosphite in glycerol did not influence the reaction (33\% conversion in 15-19 h) (Table 3,

entries 2 and 3). On the contrary, the increase of the reaction time from $15 \mathrm{~h}$ to $38 \mathrm{~h}$ afforded a conversion of $52 \%$ with $88 \%$ ee (Table 3, entry 3). Further increase of the quantity of sodium hypophosphite from 2.5 to 5 equivalents and its concentration from 2.5 to $5 \mathrm{M}$ did not significantly improve the conversion after $43 \mathrm{~h}$ (Table 3, entry 4). The amount of sodium hypophosphite under constant concentration in glycerol had a poor influence on the reaction. When sodium hypophosphite was substituted by its conjugated acid the reaction was sped up but the formation of 3 (1-phenylethoxy)propane-1,2-diol side-product was observed (Table 3, entry 5). The amount of catalyst had a positive outcome on the reaction. The increase of the catalyst loading from 2 to 4 mol- $\%$ increased the conversion from $33 \%$ to $56 \%$ in $14-15 \mathrm{~h}$ (Table 3, entries 3 and 6). When the reaction with 4 mol- $\%$ catalyst was run over $86 \mathrm{~h}$, a conversion of $70 \%$ was reached with $90 \%$ ee (Table 3, entry 6 under brackets). As the reaction remained slow, the addition of a co-solvent was considered. In toluene, the reaction was slower than in the absence of a cosolvent (Table 3, entry 7). This could be explained by the coordination competition on the catalyst between toluene and the substrate. Conversely, 2-MeTHF had a positive effect on the reaction. The conversion reached $82 \%$ and the enantiomeric excess $96 \%$ in $16 \mathrm{~h}$ (Table 3, entry 8). The increase of the reaction time to $24 \mathrm{~h}$ gave finally a conversion of $90 \%$ with $96 \%$ ee (Table 3, entry 8 ). To the best of our knowledge, this biphasic system glycerol/2-MeTHF has never been employed. Such solvent systems could be advantageously used in other sensitive reactions requiring the separation of the product from the other chemical partners. This is in agreement with the need to decrease the environmental impact of processes.

With these optimized conditions, acetophenone was converted to the corresponding $(R)$-alcohol 1 with $73 \%$ yield and $96 \%$ ee (Scheme 2). Then, the scope and limitations of the reaction were investigated. Albeit low yields, acetophenones bearing electrondonating group in para position led to the corresponding alcohols $\mathbf{1 0}$ and $\mathbf{1 1}$ with excellent enantioselectivities (91-92\% ee). Similarly, acetophenone derivatives bearing electronwithdrawing group also led to the products $5,6,16$ and 17 with the same levels of enantioselectivity (82-94\% ee) and improved isolated yields $(65-97 \%)$. Within this family, the nitrile $\mathbf{5}$ was obtained with the lowest yield $(65 \%)$ and $e e(85 \%)$ probably due to the potential ligand effect of the nitrogen. Bromoacetophenones were also readily converted to their corresponding alcohols $\mathbf{4 , 1 3}$ and 14 with no obvious effect due to the position of the substituent on the aromatic ring. Finally, compounds bearing protic functionalities such as phenol $\mathbf{1 2}$ and carboxylic acid $\mathbf{1 5}$ afforded low or no conversions. Overall, this method proved to be highly chemoselective as halide, nitro, ${ }^{[28}$ ester, nitrile and ether functional groups were not affected while retaining high levels of chiral induction $(82-94 \%$ ee $)$

Table 3. Optimisation using glycerol as protic solvent ${ }^{[a]}$

\begin{tabular}{|c|c|c|c|c|c|c|}
\hline Entry & Ru. [mol-\%] & $\begin{array}{l}\mathrm{NaH}_{2} \mathrm{PO}_{2} \cdot \mathrm{H}_{2} \mathrm{O} \\
\text { [equiv.] }\end{array}$ & $c$ in glycerol $[\mathrm{M}]$ & Additive & Time $[\mathrm{h}]$ & $\begin{array}{l}\text { Conv. }[\%]^{[\mathrm{b}]}(e e \\
\left.[\%]^{[\mathrm{c}]}\right)\end{array}$ \\
\hline 1 & 2 & 0 & I & I & 36 & 0 \\
\hline 2 & 2 & 2.5 & 0.71 & l & 19 & 33 \\
\hline 3 & 2 & 2.5 & 2.5 & l & $15(38)$ & $33(52,88 \%$ eе $)$ \\
\hline 4 & 2 & 5 & 5 & / & 43 & 53 \\
\hline 5 & 2 & 2.5 & 2.5 & $\mathrm{H}_{3} \mathrm{PO}_{2}$ (2.5 equiv.) & 17 & $61^{[\mathrm{d}]}$ \\
\hline 6 & 4 & 2.5 & 2.5 & I & $14(86)$ & $56(70,90 \% е e)$ \\
\hline 7 & 4 & 2.5 & 2.5 & toluene $([\mathrm{S}]=2 \mathrm{M})$ & 14 & 40 \\
\hline 8 & 4 & 2.5 & 2.5 & 2-MeTHF $([\mathrm{S}]=2 \mathrm{M})$ & $16(24)$ & $82(90,96 \%$ ee $)$ \\
\hline
\end{tabular}

[a] Acetophenone, $\mathrm{NaH}_{2} \mathrm{PO}_{2} \cdot \mathrm{H}_{2} \mathrm{O}$, glycerol, $\mathrm{RuCl}(p$-cymene $)[(R, R)-\mathrm{TsDPEN}], 40{ }^{\circ} \mathrm{C}$. [b] Conversions were determined by ${ }^{1} \mathrm{H}$ NMR spectroscopy on the reaction mixture. [c] Determined by chiral GC. [d] Two products were obtained: 1-phenylethanol (49\%) and 3-(1-phenylethoxy)propane-1,2-diol (12\%) 
<smiles>[R]c1ccc(C=O)cc1</smiles>

(R)-1

$73 \%, 96 \%$ ee

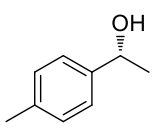

(R)-10

$51 \%, 92 \%$ ee

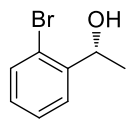

$(R)-14$

$75 \%, 92 \%$ ee
$\mathrm{NaH}_{2} \mathrm{PO}_{2} . \mathrm{H}_{2} \mathrm{O}$ (2.5 equiv., $2.5 \mathrm{M}$ in glycerol), RuCl( $p$-cymene) $[(R, R)$-TsDPEN] (4 mol- $\%)$
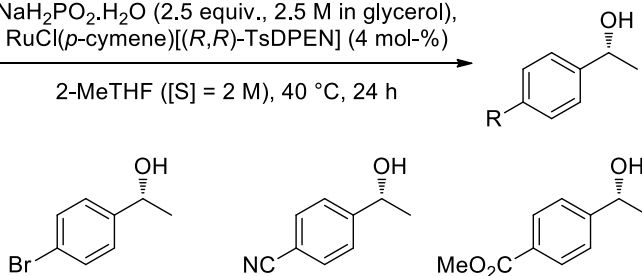

(R)-4

$74 \%, 93 \%$ ee

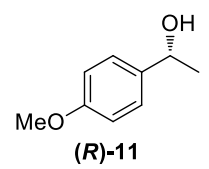

$24 \%, 91 \%$ ee<smiles>CC(O)c1ccc(C(=O)O)cc1</smiles>

15

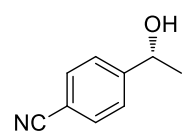

(R)-5

$65 \%, 85 \%$ ee

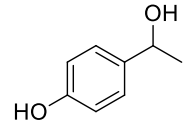

12

$0 \%$, N.D. $e e^{\star}$
2-MeTHF ([S] $=2 \mathrm{M}), 40^{\circ} \mathrm{C}, 24 \mathrm{~h}$

$10 \%$, N.D. ee*

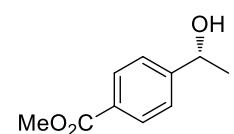

(R)-6

$97 \%, 94 \%$ ee

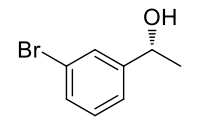

(R)-13 $85 \%, 93 \%$ ee
Configurations wiral GC or HPL ${ }^{*}$ Not isolated, conversion calculated on the reaction mixture, N.D.: not determined

Scheme 2. Enantioselective reduction of acetophenone derivatives.

The reduction of other ketone derivatives was further investigated (Scheme 3). The reduction of 2-acetonaphthone gave 3 with comparable conversion and $e e(80 \%$ yield, $96 \% e e)$ than acetophenone. Ketones bearing heterocycles such as benzo $[b]$ furan and benzo $[b]$ thiophene led to products 18 and 19 with isolated yields of 98 and $28 \%$ and enantiomeric excess of 83 and $97 \%$, respectively. The reduction of 2,6-diacetylpyridine afforded the corresponding diol 20 with $45 \%$ yield and $66 \%$ de. The major diastereoisomer was isolated with > to $95 \% e e$ in favour of the $R, R$-enantiomer. Heteroaromatic ketones bearing free $\mathrm{N}-\mathrm{H}$ bond (pyrrole and indole) have also been tested without success giving no conversion. This fact confirmed the previous observation that protic functional groups are deleterious to the reaction (Scheme 2, products 12 and $\mathbf{1 5}$ ).

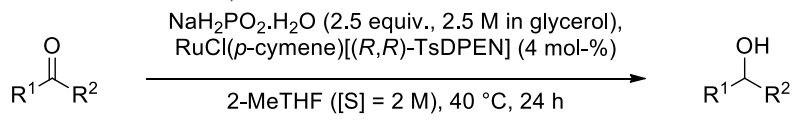

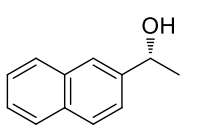

$(R)-3$ $80 \%, 96 \%$ ee

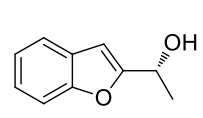

$(R)-18$ $98 \%, 83 \%$ ee<smiles>CC(O)c1cccc2scnc12</smiles>

(R)-19

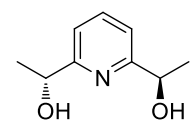

$(\boldsymbol{R}, \boldsymbol{R}) \mathbf{- 2 0}$<smiles>CCCC(O)c1ccccc1</smiles>

2
21 $0 \%$, N.D. ee*<smiles>CC(C)(C)C(O)c1ccccc1</smiles>

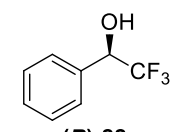

(R)-22 $5 \%{ }^{[a]}, 66 \%$ de, $>95 \%$ ee

$16 \%$, N.D. $e e^{*}$

$77 \%, 22 \%$ e

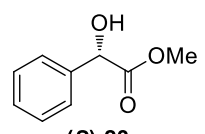

(S)-23<smiles>C[C@@H](O)CCc1ccccc1</smiles>

(R)-7, 38\%, 9\% ee

Scheme 3. Enantioselective reduction of ketones. [a] The amount of catalyst, reductive reagent and glycerol were doubled, $81 \%$ of the initial mass was recovered after extraction.

Substituents on the alkyl chain were next investigated. The derivatives with medium or bulky alkyl chain were hardly reduced to products $\mathbf{2}$ and $\mathbf{2 1}$ in 16 and $0 \%$ conversion, respectively. Methylbenzoyl formate was moderately converted and the corresponding hydroxy-ester $\mathbf{2 3}$ was obtained with $55 \%$ isolated yield and a modest induction of $66 \% e e$. The trifluoromethyl derivative $\mathbf{2 2}$ was obtained with complete conversion. The enantiomeric excess was low $(22 \%)$ and the absolute configuration was attributed to be $R$ by comparison of the measured $[\alpha]_{\mathrm{D}}$ with the literature. This means that the attacked face was the opposite than the other ketones because of the inversion of priority due to the presence of the $\mathrm{CF}_{3}$ group. The loss of enantiomeric induction from $\mathrm{CH}_{3}$ to $\mathrm{CF}_{3}$ has been already observed in the reduction with $\mathrm{RuCl}(p$-cymene)-TsDPEN and a rationalization has been proposed. ${ }^{[29]}$ The lower induction observed with $\mathrm{CF}_{3}$ has been attributed to an opposite transition state due to a poor size differentiation between the $\mathrm{CF}_{3}$ and the phenyl core. Finally, dialkyl ketones were moderately converted with low enantiomeric excess (Scheme 3, products $\mathbf{7}$ and $\mathbf{8}$ ). This could be attributed to the lack of $\mathrm{C}\left(\mathrm{sp}^{2}\right)-\mathrm{H} / \pi$ attractive interaction that is normally operating between $\eta^{6}$-arene ligand and aromatic ketones in the transition state. ${ }^{[30]}$

\section{Conclusions}

In conclusion, we have developed a general method for the reduction of ketones using sodium hypophosphite as efficient hydrogen donor. The transfer hydrogenation of aliphatic and aromatic ketones using a $\left[\mathrm{RuCl}_{2}(p \text {-cymene })\right]_{2} / 2,2$ '-bipyridine system have been achieved in water and the corresponding alcohols were isolated with moderate to excellent yields (39-95\%). Encouraged by these results, we developed the enantioselective version using $\mathrm{RuCl}(p$-cymene) $[(R, R)$-TsDPEN] in a biphasic glycerol/2-MeTHF solvent mixture. These original conditions allowed the reduction of (hetero)aromatic ketones with excellent enantioselectivities (up to $97 \%$ ee). The reactions have been conducted using bio-sourced non-toxic solvents and a cheap reductive agent - sodium hypophosphite - which has already been registered in REACH with no obvious toxicity. For these reasons, we think this reductive system could be of great interest in the context of green chemistry and could be particularly attractive for industrial applications. Current investigations are focused upon expanding the scope to a variety of functional groups.

\section{Experimental Section}

Procedure for the reduction with $\left[\mathrm{RuCl}_{2} \text { (p-cymene) }\right]_{2}$ and 2,2'-bipyridine In a sealed tube, under argon atmosphere, $\left[\mathrm{RuCl}_{2}(p \text {-cymene })\right]_{2}(15.3 \mathrm{mg}$, $0.025 \mathrm{mmol}, 1 \mathrm{~mol}-\%), 2,2$ '-bipyridine (9.4 mg, $0.06 \mathrm{mmol}, 2.4 \mathrm{~mol}-\%$ ) and sodium hypophosphite monohydrate (662 mg, $6.25 \mathrm{mmol}, 2.5$ equiv.) were introduced as solids. The ketone substrate (2.5 mmol, 1 equiv.) followed by water $\left(2.5 \mathrm{~mL}, \mathrm{c}\left(\mathrm{NaH}_{2} \mathrm{PO}_{2} \cdot \mathrm{H}_{2} \mathrm{O}\right.\right.$ in water $\left.)=2.5 \mathrm{M}\right)$ was then added. The tube was sealed. The reaction mixture was stirred at $1200 \mathrm{rpm}$ and heated at $80{ }^{\circ} \mathrm{C}$. After 24 hours, the tube was cooled to room temperature, depressurized and a ${ }^{1} \mathrm{H}$ NMR aliquot was made to check the conversion of the starting material. The reaction was diluted by additional water $(10 \mathrm{~mL})$ and extracted with either pentane or $\mathrm{CH}_{2} \mathrm{Cl}_{2}$. The combined organic extracts were dried over $\mathrm{Na}_{2} \mathrm{SO}_{4}$, filtrated and concentrated under reduced pressure. The crude material was purified by flash column chromatography on silica gel using a gradient of pentane or 
cyclohexane/ethyl acetate (1:0 to 7:3). After evaporation, alcohols were obtained as oil or solid. The products were characterized by NMR (full spectroscopic data are given in supporting information).

Procedure for the reduction with $\mathrm{RuCl}($ p-cymene) $[(R, R)$-TsDPEN]

In a Schlenk tube, $\mathrm{NaH}_{2} \mathrm{PO}_{2} \cdot \mathrm{H}_{2} \mathrm{O}(265 \mathrm{mg}, 2.5 \mathrm{mmol}, 2.5$ equiv.) and glycerol $(1 \mathrm{~mL})$ were added. The oil bath was preheated at $40{ }^{\circ} \mathrm{C}$. The reaction was flushed under argon and, under slow stirring, preformed $\operatorname{RuCl}(p$-cymene)[(R,R)-TsDPEN] (25.2 mg, $0.04 \mathrm{mmol}, 4 \mathrm{~mol}-\%)$, a ketone ( $1 \mathrm{mmol}, 1$ equiv.) and 2-MeTHF $(0.5 \mathrm{~mL})$ were quickly added. The reaction is then fluid and the stirring was increased to allow good agitation. The reaction was stirred at $40{ }^{\circ} \mathrm{C}$ for $24 \mathrm{~h}$. The treatment was similar to the previous procedure. The products were characterized by NMR and $e e$ were determined by chiral GC or HPLC (full spectroscopic and chromatographic data are given in supporting information). Configurations were determined by comparison of the measured $[\alpha]_{\mathrm{D}}$ with the literature.

Supporting Information (see footnote on the first page of this article): Characterization data, NMR spectra, GC and HPLC analyses.

\section{Acknowledgments}

The authors warmly thank the Région Rhone-Alpes for their financial support and thank F. Albrieux, C. Duchamp and N. Henriques from the Centre Commun de Spectrométrie de Masse (ICBMS UMR-5246), for the assistance and access to the Mass Spectrometry facilities.

[1] J. Magano, J. R. Dunetz, Org. Proc. Res. Dev. 2012, 16, 1156-1184.

[2] J. Seyden-Penne, Reduction by the Alumino- and Borohydrides in Organic Synthesis, 2nd Ed.; Wiley-VCH, NY, 1997.

[3] a) R. Noyori, T. Ohkuma, Angew. Chem., Int. Ed. 2001, 40, 40-73; b) for recent example: K. E. Jolley, A. Zanotti-Gerosa, F. Hancock, A. Dyke, D. M. Grainger, J. A. Medlock, H. G. Nedden, J. J. M. Le Paih, S. J. Roseblade, A. Seger, V. Sivakumar, I. Prokes, D. J. Morris, M. Wills, Adv. Synth. Catal. 2012, 354, 2545-2555.

[4] a) R. Noyori, S. Hashiguchi, Acc. Chem. Res. 1997, 30, 97-102; b) J.-E. Bäckvall, J. Organometal. Chem. 2002, 652, 105-111; c) S Gladiali, E. Alberico, Chem. Soc. Rev. 2006, 35, 226-236; d) J. Václavík, P. Kačer, M. Kuzma, L. Červený, Molecules 2011, 16 , 5460-5495; reviews on aqueous-phase transfer hydrogenation: e) X. Wu, J. Xiao, Chem. Commun. 2007, 2449-2466; f) C. Wang, X. Wu, J. Xiao, Chem.--Asian J. 2008, 3, 1750-1770; g) A. Robertson, T. Matsumoto, S. Ogo, Dalton Trans. 2011, 10304-10310.

[5] G. L. Larson, J. L. Fry in Ionic and organometallic-catalyzed organosilane reductions, John Wiley \& Sons, Inc, Hoboken, NJ, 2009.

[6] P. A. Fail, R. E. Chapin, C. J. Price, J. J. Heindel, Reprod. Toxicol. 1998, $12,1-18$.

[7] S. C. Berk, S. L. Buchwald, J. Org. Chem. 1993, 58, 3221.

[8] For recent examples: a) L. Pehlivan, E. Métay, S. Laval, W. Dayoub, P. Demonchaux, G. Mignani, M. Lemaire, Tetrahedron Lett. 2010 51, 1939-1941; b) L. Pehlivan, E. Métay, S. Laval, W. Dayoub, P. Demonchaux, G. Mignani, M. Lemaire, Tetrahedron 2011, 67, 1971-1976; c) Y. Shi, W. Dayoub, G.-R. Chen, M. Lemaire, Tetrahedron Lett. 2011, 52, 1281-1283; d) L. Pehlivan, E. Métay, O. Boyron, P. Demonchaux, G. Mignani, M. Lemaire, Eur. J. Org. Chem. 2011, 4687-4692; e) L. Pehlivan, E. Métay, S. Laval, W. Dayoub, D. Delbrayelle, G. Mignani, M. Lemaire, Eur. J. Org. Chem 2011, 7400-7406; f) L. Pehlivan, E. Métay, D. Delbrayelle, G. Mignani, M. Lemaire, Tetrahedron 2012, 68, 3151-3155; g) L. Pehlivan, E. Métay, D. Delbrayelle, G. Mignani, M. Lemaire, Eur. J. Org. Chem. 2012, 4689-4693.

[9] a) J. O. Saunders, Sodium Hypophosphite in Encyclopedia of Reagents for Organic Chemistry (Ed.: L. A. Paquette), Wiley, 1995, vol. 7, p. 4587; b) V. V. Popik, Hypophosphorous Acid in Encyclopedia of Reagents for Organic Chemistry (Ed.: L. A. Paquette), Wiley, 1995, vol. 4, pp. 2790-2792.

[10] Information on the REACH registration can be found on http://echa.europa.eu, search for chemicals: sodium hypophosphite.
[11] K. H. Krishnan, S. John, K. N. Srinivasan, J. Praveen, M. Ganesan, P. M. Kavimani, Metall. Mater. Trans. A 2006, 37A, 1917-1926.

[12] R. A. W. Johnstone, A. H. Wilby, Chem. Rev. 1985, 85, 129-170.

[13] a) Alkynes to alkenes: B. T. Khai, A. Arcelli, Chem. Ber. 1993, 126, 2265-2268; b) alkene to alkane: R. Sala, G. Doria, C. Passarotti, Tetrahedron Lett. 1984, 25, 4565-4568; c) nitro to amine: I. D. Entwistle, A. E. Jackson, R. A. W. Johnstone, R. P. Telford, J. Chem. Soc., Perkin Trans. 1 1977, 443-444; d) nitro aromatic to aromatic hydroxylamine: I. D. Entwistle, T. Gilkerson, R. A. W. Johnstone, R. P. Telford, Tetrahedron 1978, 34, 213-215; e) $\alpha, \beta$-insaturated nitroalkenes to oximes: R. S. Varma, M. Varma, G. W. Kabalka, Synth. Commun. 1986, 16, 91-96; f) imine to amine: P. Battistoni, P. Bruni, G. Fava, Synthesis 1979, 220-221; g) deoxygenation of heteroaromatic N-oxide: R. Balicki, L. Kaczmarek, Gazz. Chim. Ital. 1994, 385-386; h) carboxylic acid to aldehyde: L. J. Gooßen, K. Ghosh, Chem.Commun. 2002, 836-837; i) hydrogenolysis of C-O bond: D. V. Davydov, I. P. Beletskaya, Russ. Chem. Bull. 1993, 42, 573-576 translated from Izv. Akad. Nauk SSSR, Ser. Khim. 1993, 607-609; j) halide to alkane: C. A. Marques, M. Selva, P. Tundo, $J$. Chem. Soc., Perkin Trans 1 1993, 529-533; k) quinones to hydroquinones: I. D. Entwistle, R. A. W. Johnstone, R. P. Telford, J. Chem. Res., Synop. 1977, 117; 1) deprotection: J. Li, S. Wang, G. A. Crispino, K. Tenhuisen, A. Singh, J. A. Grosso, Tetrahedron Lett. 2003, 44, 4041-4043

[14] nitro to amine: a) E. A. Parfenov, L. D. Smirnov, Chem. Heterocycl. Compd. (N. Y., NY, U. S.) 1992, 28, 274-278; $\alpha, \beta$-insaturated nitroalkenes to carbonyl: b) D. Monti, P. Gramatica, G. Speranza, P. Manito, Tetrahedron Lett. 1983, 24, 417-418; oxime to amine: c) B. Staskun, T. Van Es, J. Chem. Soc. C 1966, 531-532; oxime to carbonyl: d) D. Monti, P. Gramatica, G. Speranza, S. Tagliapietra, P. Manitto, Synth. Commun. 1986, 16, 803-807; nitrile to aldehyde: e) O. G. Backeberg, B. Staskun, J. Chem. Soc. 1962, 3961-3963; f) B. Staskun, T. S. van Es, Afr. J. Chem. 2008, 61, 144-156; g) B. T. Khai, A. Arcelli, J. Org. Chem. 1989, 54, 949-953; reductive desulfurisation: h) M. Node, K. Nishide, Y. Shigeta, K. Obata, H. Shiraki, H. Kunishige, Tetrahedron 1997, 53, 12883-12894.

[15] nitro to amine: M. A. Mailhe, Murat, Bull. Soc. Chim. Fr. 1910, 7 , 952-956.

[16] a) nitro to amine: H. M. Meshram, Y. S. S. Ganesh, K. C. Sekhar, J. S. Yadav, Synlett 2000, 993-994; b) sulfoxide to sulphide: H. M Meshram, Y. S. S. Ganesh, K. Ramesh Babu, B. Eeshwaraiah, J. S. Yadav, Indian J. Chem. 2005, 44B, 193-195.

[17] alkene to alkane: a) O. A. Karpeiskaya, A. A. Belyi, M. E. Vol'pin, Bull. Acad. Sci, URSS, Cl. Sci. Chim. 1985, 1554 translated from Izv. Akad. Nauk SSSR, Ser. Khim. 1985, 1693; ketone to alcohol: b) B. Th. Khai, A. Arcelli, Tetrahedron Lett. 1996, 37, 6599-6602.

[18] a) S. K. Boyer, J. Bach, J. McKenna, Jr. E. Jagdmann, J. Org. Chem. 1985, 50, 3408-3411; b) V. J. Demopoulos, Synth. Commun. 1989 19, 2585-2594; c) A. F. Brigas, C. S. C. Fonseca, R. A. W Johnstone, J. Mol. Catal. A: Chem. 2006, 246, 100-108.

[19] H. B. Henbest, T. R. B. Mitchell, J. Chem. Soc. C 1970, 785-791.

[20] Reduction of aldehydes: a) J. M. Grosselin, C. Mercier, G. Allmang, F. Grass, Organomettalics 1991, 10, 2126-2133; b) N. C. Kokkinos, A. Lazaridou, N. Nikolaou, G. Papadogianakis, N. Psaroudakis, A. K. Chatzigakis, C. E. Papadopoulos, Appl. Catal., A 2009, 363, 129134; Reduction of ketone see: c) J. M. Tukacs, D. Király, A. Strádi, G. Novodarszki, Z. Eke, G. Dibó, T. Kégl, L. T. Mika, Green Chem. 2012, 14, 2057-2065.

[21] G. Chelucci, R. P. Thummel, Chem. Rev. 2002, 102, 3129-3170.

[22] a) H. Nishiyama, M. Kondo, T. Nakamura, K. Itoh, Organometallics 1991, 10, 500-508; b) D. Cuervo, M. P. Gamasa, J. Gimeno, Chem.-Eur. J. 2004, 10, 425-432.

[23] Y. Xing, J.-S. Chen, Z.-R. Dong, Y.-Y. Li, J.-X. Gao, Tetrahedron Lett. 2006, 47, 4501-4503.

[24] X. Wu, X. Li, W. Hems, F. king, J. Xiao, Org. Biomol. Chem. 2004, 2, 1818-1821.

[25] a) V. Alishoglu, G. Nedzhefoglu, Russ. J. Inorg. Chem. 1998, 43 , 1609-1610 translated from Zh. Neorg. Khim. 1998, 43, 1732-1733; b) J. Roborgh, C. A., Diss. Amsterdam 1927, S. 1/45 1927, 2356; c) S. R. Palit, J. Am. Chem. Soc. 1947, 69, 3120-3129. 
[26] R. K. Henderson, C. Jiménez-González, D. J. C. Constable, S. R. Alston, G. G. A. Inglis, G. Fisher, J. Sherwood, S. P. Binks, A. D. Curzons, Green Chem., 2011, 13, 854-862.

[27] Selected examples: a) A. Wolfson, C. Dugly, Y. Shotland, D. Tavor, Tetrahedron Lett. 2009, 50, 5951-5953; b) A. Azua, J. A. Mata, E. Peris, Organometallics 2011, 30, 5532-5536.

[28] Reduction of aromatic nitro and halide by sodium hypophosphite in presence of Pd/C: M. Baron, E. Métay, F. Popowycz, M. Lemaire, Green Chem., 2013, 15, 1006-1015.
[29] S. V. Slungård, T.-A. Krakeli, T. H. K. Thvedt, E. Fuglseth, E. Sundby, B. H. Hoff, Tetrahedron 2011, 67, 5642-5650.

[30] Mechanistic studies on Noyori catalyst: a) M. Yamakawa, I. Yamada, R. Noyori, Angew. Chem., Int. Ed. 2001, 40, 2818-2821.

Received: ((will be filled in by the editorial staff)) Published online: ((will be filled in by the editorial staff)) 
Entry for the Table of Contents ((Please choose one layout.))

\section{Layout 1:}

Hypophosphite

Sodium hypophosphite has been used in reduction of ketones in water (9 examples, $40-95 \%$ yield). An original glycerol/2-MeTHF biphasic solvent system has been developed for the enantioselective version. This system allowed the preparation of aryl-alkyl alcohols with up to $97 \%$ ee (22 examples).

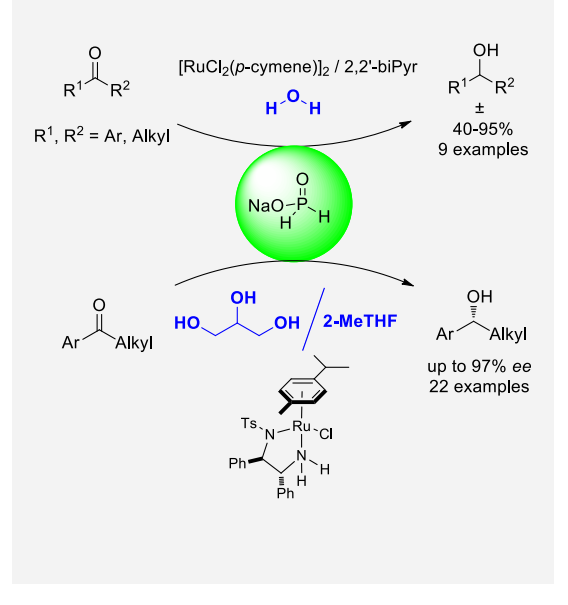

Carole Guyon, Estelle Métay, Nicolas Duguet, and Marc Lemaire* Page No. - Page No.

Biphasic glycerol/2-MeTHF ruthenium-catalyzed enantioselective transfer hydrogenation of ketones using sodium hypophosphite as hydrogen donorKeywords: Reduction / Ketone / Enantioselective / Ruthenium / Sodium hypophosphite / Glycerol

\section{Layout 2:}

((Please adjust TOC Graphic to the size of this area; max. width $11.5 \mathrm{~cm})$ )

((Text for Table of Contents))
((Text for Table of Contents, Continued - max. 350 characters; not the same text as the Abstract))
((Author(s), with * for Corresponding Author(s))) ......... Page No. - Page No.

$(($ Title $))$

Keywords: ((Keyword 1 / Keyword 2 / Keyword 3 / Keyword 4 / Keyword 5)) 
